\title{
Miranda
}

Revue pluridisciplinaire du monde anglophone /

Multidisciplinary peer-reviewed journal on the English-

speaking world

$18 \mid 2019$

Guerre en poésie, poésie en guerre

\section{Alexandra Lapierre, Avec toute ma colère. Mère et fille : le duel à mort. Maud et Nancy Cunard}

\section{Christine Dualé}

\section{OpenEdition}

\section{Journals}

Édition électronique

URL : http://journals.openedition.org/miranda/17229

DOI : 10.4000/miranda. 17229

ISSN : 2108-6559

Éditeur

Université Toulouse - Jean Jaurès

\section{Référence électronique}

Christine Dualé, «Alexandra Lapierre, Avec toute ma colère. Mère et fille : le duel à mort. Maud et Nancy

Cunard », Miranda [En ligne], 18 | 2019, mis en ligne le 16 avril 2019, consulté le 16 février 2021. URL

http://journals.openedition.org/miranda/17229 ; DOI : https://doi.org/10.4000/miranda.17229

Ce document a été généré automatiquement le 16 février 2021.

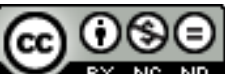

Miranda is licensed under a Creative Commons Attribution-NonCommercial-NoDerivatives 4.0 International License. 


\section{Alexandra Lapierre, Avec toute ma colère. Mère et fille : le duel à mort. Maud et Nancy Cunard}

\section{Christine Dualé}

\section{RÉFÉRENCE}

Alexandra Lapierre, Avec toute ma colère. Mère et fille : le duel à mort. Maud et Nancy Cunard. (Paris, Flammarion, 2018) 343 p, ISBN : 978-2-0813-3283-6.

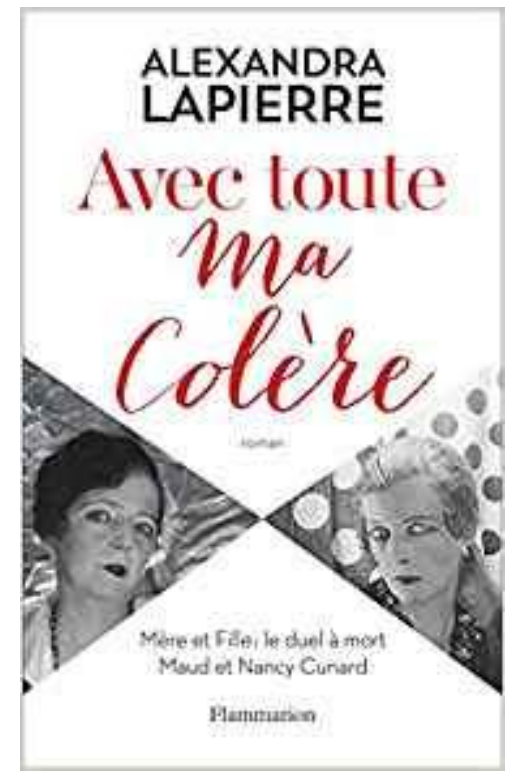

Photographiée par Man Ray en 1926 les avant-bras parés de ses bracelets d'ivoire dont elle tirait une grande fierté, Nancy Cunard est certainement plus connue du grand public pour ce portrait qui incarne la beauté et l'élégance féminine des années folles et 
son image de "femme fatale » (23) que pour son engagement intellectuel. «Dès leurs premiers romans, Aldous Huxley et Michael Arlen la décrivent comme une croqueuse d'hommes. Une vamp. L'archétype de la séductrice d'après-guerre " (23). Son rôle majeur et son action dans le monde intellectuel sont pourtant indéniables, elle qui fut une icône, une muse, adulée des artistes et des intellectuels. D'ailleurs, nombreux sont ceux qui louèrent sa « virtuosité intellectuelle » (197).

Dans son essai The Fighting Lady (1926), Georges Sadoul reconnait : "s'il y eut jamais dans ce siècle une Lady, une grande dame dans le vrai sens du terme, par son intelligence, sa culture universelle, son courage, son désintéressement, ce fut Nancy Cunard » (29) et il ajoute : « l'allure de Nancy frappait et retenait. On voyait d'abord ses yeux très bleus, assez étranges; son visage fin et osseux; la crinière léonine de ses cheveux blonds; puis on s'étonnait de voir ses bras minces, recouverts, des poignets aux épaules, par des bracelets africains en ivoire, dont elle avait la passion » (29-30). On sait aussi très peu sur la mère de Nancy, Maud Cunard, mécène des arts, «l'incarnation de la muse et de la mécène américaine, dans l'Angleterre de Churchill. Le type même de la femme de pouvoir durant l'entre-deux-guerres » (22) qui influença la haute société britannique pendant la première moitié du vingtième siècle.

3 Sur la base d'évènements ayant réellement eu lieu, Alexandra Lapierre fait remonter avec émotion et sensibilité les souvenirs de Maud et Nancy Cunard afin de retracer leur relation conflictuelle. À travers les portraits croisés de ces deux femmes singulières et paradoxales, Alexandra Lapierre entraîne ses lecteurs dans la vie tumultueuse et romanesque de deux personnalités flamboyantes de l'entre-deux-guerres. Habituée des biographies de femmes oubliées, elle nous fait cette fois découvrir le conflit mère-fille, la tragédie entre Lady Maud-Emerald Cunard et Nancy Cunard; " deux lutteuses qui auraient pu s'aimer mais ne cessèrent de se manquer, tels deux amants dont les élans ne coïncident jamais » (11). Mais ce roman est aussi une enquête, menée de main de maitre par Alexandra Lapierre, pour décrire ce huis clos psychologique et comprendre « les blessures qu'elles s'étaient infligées l'une à l'autre » (21). Le roman s'appuie sur les traces laissées par chacune des actrices de ce drame mais aussi par l'entourage proche. Alexandra Lapierre confie à ce propos : «j'ai reproduit leurs propres paroles dans mes dialogues et mes interrogatoires. Et je me suis systématiquement appuyée sur les écrits des témoins de leurs causes » (12).

4 Le roman se divise en cinq parties, nous pourrions même dire cinq actes car la vie de Maud et Nancy Cunard s'est jouée comme une pièce de théâtre, une tragédie grecque. Après l'évocation des raisons ayant poussé Alexandra Lapierre à écrire ce roman dans le livre premier («L'affaire Cunard»), elle nous fait découvrir le monde de Maud et Nancy Cunard en revenant sur leur passé et en les faisant parler. Le livre second («L'ombre, l'image et le double») revient sur les origines du conflit entre les deux femmes et le rôle de Diane Cooper, fille illégitime du Duc de Rutland, amie intime de Maud et de Nancy et à laquelle Alexandra Lapierre donne le rôle de médiatrice afin de tenter de résoudre la rupture entre la mère et la fille.

$5 \quad$ Le lecteur apprend beaucoup sur le passé de Maud Cunard tout au long du roman mais aussi à travers le livre troisième ("Histoire de Maud») où Alexandra Lapierre se livre aux portraits croisés de ses deux héroïnes. Si Nancy Cunard fut influente dans le Paris des années folles, sa mère, Maud Cunard, le fut tout autant dans l'Angleterre de la Belle Époque et il est très intéressant de voir à quel point ces deux femmes jouèrent des rôles non négligeables dans l'histoire intellectuelle et artistique de leur époque. 
6 Maud Alice Burke, mondaine américaine, est devenue Lady Maud Emerald Cunard en se mariant à l'aristocrate anglais Bache Cunard, héritier de la flotte de paquebots The Cunard Line. Remariée, maîtresse de l'écrivain George Moore pendant de nombreuses années puis du chef d'orchestre Thomas Beecham, Maud Cunard va vivre à sa guise et se consacrer entièrement à la musique ce qui la mène à délaisser sa fille dont la grande solitude est perceptible très tôt. Dépourvue d'instinct maternel, Maud Cunard disait d'ailleurs: "c'est tellement vulgaire d'avoir des enfants!» (124). Nancy est donc confiée à des nurses et des gouvernantes, s'évade grâce à la lecture et tente d'oublier la jalousie supposée de sa mère. Elle côtoie aussi les amants de sa mère et commence, par son intermédiaire, à entretenir des relations ambiguës avec eux. Le cadre du conflit est alors posé: «her Ladyship ne supportait pas que j'aie une relation avec lui [George Moore]. Elle se montrait envers nous d'une jalousie féroce. Et ni l'un ni l'autre, nous ne nous en apercevions, tant elle était habile à manipuler nos sentiments... Je me souviens d'un drame à propos d'un roman que j'avais lu en cachette. Mon premier roman. [...] G.M. m'a surprise dans la bibliothèque, le livre à la main, et nous en avons longuement discuté tous les deux. Le malheur a voulu que Miss Scarth [ma gouvernante] entende notre conversation et la rapporte à Milady. Je te laisse imaginer le pugilat » (136-137).

7 Installée à Londres en 1911 (au 20 Cavendish Street, précisément) Maud Cunard transforme la décoration de son hôtel particulier, fait se rencontrer des artistes d'avant-garde et reçoit tout ce qu'il y a de plus nouveaux et de plus bohème; elle réussit ainsi à conquérir l'aristocratie anglaise. Avec son amant, le chef d'orchestre Thomas Beecham, ils introduisent Nijinski à Londres et imposent les Ballets Russes, «l'aventure la plus excitante» (144) que Maud Cunard ait jamais connue. À cette époque, Nancy a déjà quinze ans, elle se sent très seule et s'ennuie aussi beaucoup car « elle trouvait la terre entière rasoir » (181). Le décor du conflit qui va se jouer est alors définitivement planté.

8 Nancy est née en Angleterre en 1896. "Sa mère, Maud Alice Burke, est américaine et son père, Bache Cunard, anglais, héritier de l'entreprise maritime Cunard Line. Elle passe son enfance au château de Neville Holt, dans le centre de l'Angleterre, élevée par des gouvernantes au rythme des fêtes organisées par sa mère, Lady Cunard. Adolescente, elle voyage, étudie dans une école prestigieuse de Londres, en France et en Allemagne, et suit sa mère dans ses activités mondaines. C'est à la veille de la première guerre mondiale, à ses 18 ans, qu'elle entame sa vie de jeune fille libre, bohème et provocante qui cherche à s'affranchir des règles de l'Angleterre victorienne » (FriouxSalgas, Introduction "L'Atlantique noir " de Nancy Cunard, Negro Anthology, 1931-1934, Gradhiva, 19|2014, 7).

9 Nancy Cunard va devenir ainsi le symbole de l'avant-garde anglo-saxonne et française en évoluant parmi les intellectuels avant-gardistes et surréalistes de son époque. Elle est le symbole de la liberté féminine dans une société dominée par le poids des traditions. «Sa beauté, ses audaces, son goût pour l'excès, son appétit pour les hommes et pour les femmes avaient provoqué une multitude de scandales qui éclatèrent à Londres, à New York et à Paris pendant l'entre-deux-guerres » (20). Elle séduit T.S. Eliot et entretien une liaison avec Ezra Pound. Nous apprenons aussi qu'elle vit pour l'écriture et publie ses premiers poèmes. À vingt-quatre ans, après un avortement dans de mauvaises conditions, elle décide de ne pas avoir d'enfant afin de ne pas reproduire le même schéma mère-fille qu'elle vit avec sa mère. Éprise de liberté absolue, elle 
souhaite «ne pas reproduire ces appels dans le désert » (213) mais aussi bénéficier « d'une liberté sexuelle totale » (212).

Le livre quatrième ( Avant me submerge comme une vague immense ») fait ressurgir le passé et la voix du pianiste de jazz Henry Crowder, amant de Nancy Cunard avec qui elle va faire l'expérience du racisme. Elle lui fait rencontrer ses proches, Ezra Pound, Somerset Maughan, Louis Aragon et Diane Cooper et l'installe dans sa maison du Puits Carré en Normandie qu'elle habite de 1927 à 1948. En donnant la parole à Henry Crowder (dans Henry-Music 239-263), le lecteur apprend l'intérêt et l'engouement grandissants de Nancy Cunard pour la culture noire américaine : "sa curiosité pour la communauté afro-américaine ne cessait de grandir. Elle s'intéressait sérieusement à la culture noire. [...] [Elle] m'interrogeait constamment sur ce qu'impliquait la ségrégation dans les écoles, les restaurants, les théâtres et les lieux publics aux États-Unis. Elle me parlait d'un projet: l'élaboration d'un livre sur l'histoire de la négritude. Elle rêvait d'un grand voyage de recherches en Afrique, avec moi » (258).

11 Ce projet de livre s'est évidemment concrétisé puisqu'il s'agit de Negro: An Anthology publié en 1934, première collaboration rassemblant cent cinquante-cinq auteurs d'origines diverses et «la justification de ma vie » (268) comme Alexandra Lapierre le fait dire à Nancy Cunard. Cet ouvrage est aussi le résultat des activités d'éditrice et d'imprimeur de Nancy puisqu'elle fonda, avec l'aide de Louis Aragon, sa propre maison d'édition en 1928, Hours Press. Negro regroupe de nombreux contributeurs qui sont « militants, intellectuels, journalistes, artistes, poètes, universitaires, anthropologues, Africains-Américains, Antillais, Africains, Malgaches, Latino-Américains, Américains, Européens, femmes et hommes. Certains d'entre eux sont colonisés, discriminés, ségrégués » (Frioux-Salgas 5). Nancy Cunard a toutefois publié en 1931 Black Man and White Ladyship : An Anniversary, un pamphlet en réaction contre sa mère, le racisme et l'homophobie de la société qu'elle représentait; son "matricide littéraire » (276) en définitive. En se révoltant contre la culture blanche pour l'une et en s'opposant à la relation avec Henry Crowder pour l'autre, la fille et la mère se livrent un combat sans relâche à travers Henry Crowder : " pauvre Ladyship...Physiquement malade à l'idée du contact de sa chair et de son sang avec une peau de Noir. Un dégoût insurmontable. [...] Une caricature de petite Yankee du Ku Klux Klan» (272-273). Ce combat atteint son paroxysme dans le livre cinquième (« L'affrontement ») où Maud et Nancy règlent leurs comptes. Nancy apprend que sa mère a commandé un rapport sur Henry Crowder et comprend que la vraie raison de son opposition est sa couleur de peau puisque selon Maud «les Noirs et les Blancs ne sont pas faits pour se mélanger» (287); Henry Crowder était à ses yeux «le Nègre de Nancy " (290). Le racisme de Maud Cunard est certes indéniable. Toutefois, l'attitude de Nancy vis-à-vis d'Henry Crowder reste paradoxale. Dans sa biographie de Nancy Cunard, Ann Chisholm (Nancy Cunard: A Biography, 1979) révèle :

Il [Henry Crowder] était très patient et presque embarrassé dès que Nancy lui demandait d'être plus noir ou qu'il se comporte de façon plus primitive ou exotique. "Sois plus Africain, sois plus Africain », lui demanda-t-elle un soir, se souvient Harold Acton. « Mais je ne suis pas Africain, je suis Américain', lui répondit Crowder très gentiment (Chisholm 101; ma traduction).

Si Nancy ne partageait aucun des préjugés de sa mère et a lutté sans relâche contre le racisme, sa vision et sa compréhension de la culture noire américaine furent celles de son époque et témoignent d'une forme d'ignorance empreinte de la culture blanche 
colonialiste. Henry Crowder reste malgré tout son grand amour, « la référence absolue de l'existence » (267), «LE point fixe » (266) dans la vie de Nancy Cunard.

Le livre cinquième clarifie aussi ce que le lecteur pressentait déjà et permet de comprendre la rage de Nancy et son conflit de toute une vie avec sa mère qui ne voulut jamais admettre l'ambiguïté et la perversité d'un de ses amants avec sa propre fille alors âgée de quatorze ans. Le voile est définitivement levé sur ce besoin de renouveau permanent et cette angoisse du passé. Maud Cunard décède en 1948 et ne déshérite pas totalement sa fille mais Nancy n'est pas libérée pour autant. Elle voyage beaucoup et « sa vie reste une fuite en avant, une course éperdue vers l'Ailleurs » (315).

Cette vie tragique, " prise au piège d'une mère qu'elle dérangeait dès sa naissance, d'un milieu, d'un monde, d'un siècle qu'elle devançait» (319) prend fin avec «En guise de post-scriptum ». Nancy Cunard décède en 1965 seule et oubliée de tous. Auparavant, Alexandra Lapierre nous informe qu'elle avait été déclarée atteinte de démence éthylique en 1960. "Son corps s'était consumé dans une longue bataille contre l'injustice en ce monde, écrira Neruda. Elle n'en avait reçu d'autre récompense qu'une vie chaque fois plus solitaire, et une mort dans l'abandon » (317).

C'est avec une émotion palpable qu'Alexandra Lapierre nous amène au terme de la vie de Nancy Cunard redevenue, grâce à ce roman biographique, ce qu'elle n'a cessé d'être : " porte-parole et précurseur de toutes les grandes causes d'aujourd'hui [et qui] éclaire le présent comme un phare » (319). Ce sont ses combats, sa force et sa liberté absolue qui demeurent et qu'Alexandra Lapierre fait originalement revivre ici. Les combats d'« une femme sans contraintes ni limites. Sans entraves sociales, sans entraves intellectuelles, sans entraves sexuelles»(18), tout simplement, les combats d'une femme d'exception.

\section{INDEX}

Keywords : Anger, aristocracy, bohemian life, black culture, conflict between mother and daughter, cult of the art, freedom, Hours Press, music, patroness of the arts, racism, rage, revolt, roaring twenties, Russian Ballets, salon, unfairness, xenophobia

Mots-clés : Années folles, aristocratie, Ballets Russes, bohème, colère, conflit mère-fille, culte de l'art, culture noire, Hours Press, injustices, liberté, mécène, musique, racisme, rage, révolte, salon mondain, xénophobie

\section{AUTEURS}

\section{CHRISTINE DUALÉ}

Maître de conférences HDR

Université Toulouse Capitole

christine.duale@ut-capitole.fr 